\title{
$O$ Valente e a Farda: as peripécias de um narrador e sua indumentária nas secas do Ceará
}

The brave and the uniform:
a narrator's adventures during the droughts of Ceará
Kênia Sousa Rios

Apresentação

Este texto faz parte originalmente da tese de doutorado defendida na PUC-SP, em 2003, intitulada Os engenhos da memória. A tese, cuja pesquisa foi financiada pela FAPESP, está centrada no estudo das composições narrativas sobre a memória da seca no Ceará, sobretudo em 1932 e 1958.

Muitos narradores foram ouvidos no decorrer da pesquisa, realizada de 1999 a 2002. Um deles, "seu" Muriçoca, ocupou maior espaço por sua vocação como narrador. Homem da fala. De narrativas em que os objetos aparecem como protagonistas, criando e sendo criados na peleja de homens e mulheres que habi-

Kênia Sousa Rios é professora de Teoria da História do Departamento de História da Universidade Federal do Ceará, Fortaleza, Brasil (keniatal3@hotmail.com).

Artigo recebido em 30 de junho de 2011 e aprovado para publicação em 12 de setembro de 2011.

Est. Hist., Rio de Faneiro, vol. 24, no 48, p. 351-365, julho-dezembro de 2011. 
tam ou habitaram as terras do Ceará e que, portanto, guardam histórias da seca nas suas múltiplas interfaces com as "invenções do cotidiano".

Nessas memórias da seca no Ceará, a cultura material passa a ser matéria da voz, objetos e corpos são narrados com o desejo de tornar a fala um texto visual. Eles se juntam e se separam, dando sentido à vida desses indivíduos.

\section{O traje de Muriçoca}

Na primeira entrevista, em 1999, "seu" Muriçoca chegou uma hora depois do combinado. Vestia uma calça azul marinho com pregas na frente, de comprimento que chegava ao tornozelo, permitindo a visão da meia branca dentro de um tênis já quase cinza pela ação das inúmeras lavagens. Quando sentava, a calça era suspensa quase ao meio da canela, fina e comprida. A camisa de linho branco, por dentro da calça, pontuava-se de esgarçamentos, cuidadosamente cingidos à máquina com linha igualmente branca. Um cinto preto, preso em seu último furo, franzia o cós da calça, que se enchia de pregas.

Um chapéu preto, que lembrava os quepes de operários italianos das primeiras décadas do século XX, prendia os cabelos brancos que saltavam por trás das grandes orelhas. Vez por outra, tirava o boné e com uma das mãos alisava o cabelo para trás, tentando organizar os fios espalhados pelo vento. Devidamente "lambidos", os cabelos se ocultavam embaixo do chapéu que escondia metade da testa.

Trazia embaixo do braço uma pasta de couro preto, do tamanho de um caderno médio. Durante a entrevista, essa pasta oscilava entre o seu colo e o banco ao lado dele. Portou esse utensílio quase todas as vezes que nos encontramos. Nunca perguntei o que ele guardava, mas hoje arriscaria uma opinião sobre a pasta: penso que fazia parte da indumentária que escolheu para as entrevistas. "Seu" Muriçoca não se veste ou carrega coisas à toa, ele reconhece os sentidos dessas “coisas". Pensa em cada detalhe, combinando os objetos à sua narrativa e, com eles, vai expondo seus enunciados. Põe o objeto no movimento do corpo, compondo significados vários. Não se trata de pensar a história da roupa militar ou coisa parecida. O que nos aproxima da farda de "seu" Muriçoca é o uso que ele fazia da veste, no sentido que Michel de Certeau sugere pensar: “(...) os utensílios (...) são marcados por usos; apresentam à análise as marcas de atos ou processos de enunciação" (Certeau, 1994: 82).

"Seu" Muriçoca é um senhor de quase dois metros, pele escura, cabelos grisalhos, andar vigoroso, levemente curvado. Sua voz rouca, sem as perturbações clássicas da idade, articula-se no vaivém dos braços, que também sobem e descem de acordo com o assunto em pauta. Os dedos magros, vez por outra, esticam-se mais próximos do meu rosto para indicar o tamanho de alguma coisa dita. 
Uma espessa sobrancelha grisalha ergue-se sobre os olhos vivos, apesar da catarata que começa a tomar conta do lado direito. A boca grande tem voz compassada e clara, apesar da ausência de alguns dentes. Narra sem grandes pausas e se diverte com a minha falta de entendimento sobre alguns termos arcaicos.

Com a farda sempre bem lavada e engomada, "seu" Muriçoca, aos 89 anos, não falta a uma noite de espetáculos no Teatro José de Alencar. Recebe os bilhetes de todos os que entram e, com um franco "Boa noite", cativa os frequentadores do teatro, lugar onde transita com intimidade conjugal.

Já nas primeiras entrevistas, era possível perceber algumas vaidades de "seu" Muriçoca. A maior delas era justamente sua conexão com o teatro. Como ele mesmo diz, foi lá que aprendeu a "ser gente de verdade" e, no mesmo período, transformou-se em Muriçoca. Era como se tivesse nascido um outro homem; não era mais Cassiano, o homem do roçado, da fome no sertão, dos trabalhos subalternos. Das diversas relações com o teatro, surgiu o "seu" Muriçoca, homem que conhece as figuras mais ilustres da cidade e artistas de fama nacional. Além disso, o teatro deu a Muriçoca a possibilidade de transformar o Quasímodo num Hércules.

O Teatro José de Alencar foi o primeiro lugar onde pisou quando veio ter em Fortaleza. Naquele mesmo dia, realizou o sonho de ser soldado. Além disso, contemplou outro desejo, o de conhecer a capital. Chegou em Fortaleza, dirigindo-se mais precisamente para o teatro, que serviu de alojamento aos soldados a serem transferidos para São Paulo por ocasião da Revolução Constitucionalista de 1932. Em primeira página, o jornal O Povo do dia 27 de agosto de 1932 anunciava: "Para o novo batalhão provisório já se acham alistados 201 voluntários e existem cerca de cem por alistar nesta capital."

Houve uma intensa campanha por todo o sertão nordestino arregimentando soldados para combater os constitucionalistas, em São Paulo. Uma das levas trouxe "seu" Muriçoca a Fortaleza, para os alojamentos do Teatro José de Alencar. Mesmo sem saber direito o que ia combater, veio com entusiasmo.

Alguns dias depois da chegada à capital, tendo enfrentado mais uma "pecaminosa" refeição, Cassiano tentou, em vão, dormir. O peso da comida ruminava em seu estômago e aliava-se a barulhentos fogos de artifício, como que indicando o desenlace da guerra. Pela manhã, o sargento reuniu todos e anunciou, com entusiasmo, o final vitorioso da tal revolução.

Cassiano não conseguiu partilhar daquela satisfação. Retornaria para casa sem ter combatido, voltaria para a fome sem ter conhecido São Paulo. Foi obrigado a regressar para o Crato sem essas histórias. Contudo, 70 anos depois, pode contar muitas outras, em nome de um valioso utensílio que carregou na sua mala: A FARDA. 
"Seu" Muriçoca conta com entusiasmo as peripécias que conseguiu realizar com a roupa que herdou do Exército. Desde então, a vestimenta passou a ter um significado especial. Recorreu à farda em vários momentos de sua vida. Cedo percebeu que o lugar do poder passa também pela indumentária e que as coisas, como roupas e panelas, não são meros objetos: elas fazem parte do movimento da vida. "Seu" Muriçoca tinha (e tem) fardas, e a elas recorre sempre que julga necessário.

Compreendi que não era possível falar de "seu" Muriçoca sem descrever sua roupa e sua pasta. Em verdade, somente no momento em que contava suas aventuras com a farda é que olhei atentamente para os trajes e utensílios que portava. Tornara-se impossível descrever "seu" Muriçoca sem falar de suas roupas.

Em 1932, desempregado, ele e mais dois amigos foram para casa. "Voltaram da guerra", para a alegria da mãe que teve o filho são e salvo. E, ao contrário da curta e farta vida de soldado que experimentou, em casa não havia nada para comer. Quando chegou, a mãe chorava de alegria,

porque eu tinha chegado, e chorando mais porque não tinha nada pra comer. Aí ficaram olhando. Meu pai sentado no banco à moda Jeca Tatu: - Meu filho, num tem nada pra comer. Tava só a panela de barro emborcada em riba do jirau. Eu disse: - Mãe, num precisa não, que eu tenho dinheiro aqui. Eu passei na bodega, tem muita coisa lá. Dei cinco mirréis a papai, ele foi depressa comprar arroz, feijão, comprar umas tripa de gado, de porco.

A lembrança da fome durante a seca é arrematada por uma narrativa cheia de detalhes, imagética. A panela de barro emborcada no jirau é o anúncio da total ausência de comida. A posição do objeto anunciava a fome, mas "seu" Muriçoca estava de posse de um outro utensílio, capaz de desemborcar a panela.

O sentido das coisas não é anunciado somente por palavras. $\mathrm{O}$ corpo do pai envergonhado se compunha com o objeto de barro emborcado no jirau. O pai era o mais desrespeitado com a situação. Ele era o Jeca Tatu, o franzino e fraco que se rendera às dificuldades da vida. A mãe chorava, mas o pai tinha seu corpo enroscado tal qual a panela no jirau.

A seca diminuía a culpa do pai, mas "seu" Muriçoca não lhe concedeu plena absolvição, pois, ao contrário do pai, ele não se resignou. Lutou com o que dispunha, criou oportunidades, recriou o sentido das coisas. Naquele momento, "descobriu" a roupa como mais uma aliada nas artimanhas que a vida solicita. Alistou-se para ser soldado, e, entre outras coisas, para vestir uma farda. Da pri- 
meira opção desvencilhou-se rapidamente, e da farda fez companheira de longa jornada. Naquele momento, Cassiano começou a existir de outro modo, fazia-se na relação com aquele objeto como um duplo que define o sujeito que faz e que é feito pela coisa, como ressalta Bruno Latour: “(...) possuímos centenas de mitos contando como o sujeito (...) construiu o objeto. Não temos, entretanto, nada para nos contar o outro aspecto da história: como o objeto faz o sujeito" (Latour, 1994: 28).

Sem esperar pela reação do pai, Cassiano chegou e logo providenciou a refeição daquele dia. Sem descanso, começou a articular o enfrentamento das dificuldades vindouras, o que incluía, sem dúvida, o uso da farda. Rapidamente pediu que a mãe preparasse sua roupa. Mesmo sem ter combatido em São Paulo, entendia que, em certo sentido, continuava na guerra. A mãe sem demora preparou-lhe a armadura:

(...) minha mãe pegou a farda que tava num saco. Passou no ferro. Eu vesti e fui pra casa dos meus amigos Zé Ferreira e Chiquim. Fumo passear na rua. O pessoal tudo admirado, nós com aquela farda bonita. Todo mundo pensava que a gente era soldado ainda. Os soldados da cidade passava pela gente, fazia continência e a gente também. Ninguém perguntava nada.

Nem mesmo "seu" Muriçoca sabia o tamanho prestígio daquela roupa. Admirava-se com cada sentimento de poder que experimentava. Quando narra, recria a surpresa diante do poder que a farda lhe deu. Refaz a importância da roupa, mas, antes de tudo, gostou do que lhe aconteceu naqueles dias:

De noite nós fumo no cinema, na praça Siqueira Campos. O gerente do cinema, nós quis comprar, ele disse: "Não, vocês pode entrar”. A gente gostava de assistir aqueles filme de caubói, nós assistimo cinema de graça. Todo mundo admirado.

Tamanha admiração, narrada por "seu" Muriçoca, partilha do sentido que ele mesmo atribui à farda. Os valores ressaltados participam, sobretudo, das conexões que ele estabelece com a indumentária, mas que, em certa medida, encontravam eco naquela pequena cidade onde vivia. "Seu" Muriçoca fez uso dos significados partilhados coletivamente em face daquela vestimenta. Em nome da roupa, o flagelado transformara-se no protetor da cidade. Vale destacar a reflexão de Mello e Souza sobre a vestimenta como linguagem simbólica, 
um estratagema de que o homem sempre se serviu para tornar inteligíveis uma série de ideias como o estado emocional, as ocasiões sociais, a ocupação ou o nível de importância do portador (Mello e Souza, 1996: 125).

É ainda Gilda de Mello e Souza que argumenta: “Ora, nesse impulso de identificação das classes, a vestimenta talvez seja o sinal mais eficaz de influência direta sobre o próximo" (Mello e Souza, 1996: 124). O caso aqui estudado ajuda a pensar que essa inferência da autora é válida para colocar a roupa como objeto que (in)veste os sujeitos dos mais variados significados, extrapolando, inclusive, os sentidos de classe.

Aquela roupa moldava o corpo de Cassiano. Imprimia-lhe novos sentidos. Produzia novas relações com o mundo. Seu novo corpo sentia-se forte, com pele nova. Seus braços e pernas aceitaram com entusiasmo o membro recém-chegado. Configurava-se um jogo em que ficava difícil saber quem seduzia ou era seduzido. A descrição feita aqui privilegia um olhar que tenta enxergar "seu" Muriçoca através de rabiscos que desenham o vivido, sem desprezar os fractais do mundo sensível. O desafio é romper com ideias polarizadas entre sujeito e objeto, o corpo e as coisas, ou ainda, "seu" Muriçoca e a farda.

As memórias de "seu” Muriçoca buscam lembranças detalhadas de uma época em que ainda era Cassiano, mas que, no entanto, já começava a entender os desmantelos do mundo. Entre eles, o privilégio de uns diante da miséria de outros. "Seu" Muriçoca fazia e faz parte do segundo grupo e cedo teve que aprender alguns "macetes" da luta pela sobrevivência; entre esses recursos, estava o uso estratégico da indumentária.

No dia seguinte, de novo paramentou-se. Juntamente com seus amigos Zé Ferreira e Chiquim, devidamente fardados, foi para a feira do Crato. Era diferente dos outros, embora passasse pela mesma fome. Tornara-se forasteiro dentro da sua própria cidade, diante de pessoas que o conheciam desde a infância. Difícil saber quem tinha mais prestígio, ele ou a farda. Naquele momento formavam um. Aproveitando-se da perfeita composição, os dois (farda e Muriçoca) se transformaram em ilustre e garboso rapaz.

Conta que olhavam para ele com estranheza. A cidade lhe fazia continência. Para incrementar a história, "seu" Muriçoca relata como ludibriou de maneira cômica um fardado do alto escalão; como fardas e fardas se reconhecem e se enganam. Porque "o ser do objeto existe na relação com o ser humano mas também com o ser dos outros objetos” (Ramos, 2004: 62). Lembra ele:

Na feira do Crato os matuto tudo admirado. Nós tudo abotoado e engomado. Nove horas do dia chegava um trem da Paraíba, o 
Paraibano. Ia pra feira do Crato. A gente lá, aquele horror de gente. O Ferreira disse:- Olha quem vem acolá, é o tenente Alfredo Dias, comandante da companhia em Juazeiro. - Vixe Maria, e agora? Nós tudo fardado. Com o fardamento completo. De longe se aproximou, vei direto na nossa direção. Ficamo duro, mas fizemo a continência. Nos cumprimentou. Ficamo com medo dele perguntar qual era a missão nossa.

Estavam em perfeita composição com aquilo que vestiam. Quem desconfiaria que aqueles soldados não mereciam a farda? Quem ousaria dizer que não sabiam usar a farda? $\mathrm{O}$ tenente nem desconfiou, mas atrapalhou o dia. Não puderam se mostrar aos outros, aos matutos. No primeiro momento, não se preocuparam tanto em arranjar um emprego; queriam ser vistos, admirados, mas o "desgraçado do tenente" desmanchou os planos de "seu" Muriçoca, Zé Ferreira e Chiquim. Entretanto, reafirmou a interação dos três rapazes com aquilo que trajavam. Aquela vestimenta exigia um tipo de corpo e, ao que tudo indica, eles obedeceram rigorosamente a tais condições. Novamente Gilda de Mello e Souza faz um bom arremate para a reflexão “(...) o indivíduo tende a revelar o seu nível não tanto pela fazenda, o chapéu, as jóias, mas pela educação, jeito de andar, maneiras" (Mello e Souza, 1996: 137). Mesmo considerando que a autora fala das formas de distinção que se colocam entre nobres e plebeus, aristocratas e burgueses etc., vale pensar que "seu" Muriçoca aderiu a alguns modos de ser/estar necessários para estabelecer semelhança com as outras fardas que circulavam pela cidade.

A importância da indumentária é reconhecida por muitos, além de "seu" Muriçoca. A maioria sabe que a aparência construída com a ajuda da roupa pode mudar o rumo das coisas. Assim como Muriçoca, "seu” José Valmir também se vestiu para enfrentar as agruras da seca.

"Seu" José Valmir preparou a indumentária na tentativa de criar um novo corpo, que parecesse mais adulto e responsável. Assim o fez. Na seca de 1958, jovens e adultos eram alistados na construção de açudes e estradas de rodagem. Os indivíduos abaixo de 16 anos recebiam metade do ponto. Com apenas 15 anos, "seu" José Valmir não se conformava em receber metade do salário pelo mesmo trabalho que faziam os outros. No lugar de uma calça curta e pés no chão, tratou de vestir-se como adulto. Sua mãe fez uma calça comprida com vários retalhos que conseguiu juntar e botou sapato no filho, que se "fingia" de adulto.

Com isso, "seu” José Valmir afirma que conseguiu receber o ponto inteiro, pois "a roupa de gente grande enganava direitinho os fiscal das obra". O uso da roupa certa é uma das táticas de sobrevivência nos caminhos traçados por esses indivíduos. Estar adequado não significa exatamente estar bem vestido, com 
roupas caras e bem compostas. A finalidade da indumentária é que define seu bom uso para diferentes situações. Dependendo da situação, pode ser melhor vestir-se de farrapos. Nesse sentido, a indumentária participa dos "jogos de ação relativos a tipos de circunstâncias", expressão de Michel de Certeau para definir aquilo que seguramente "seu" Muriçoca e "seu" José Valmir fizeram com seus trajes, uma vez que tal objeto ganha sentido na medida em que são evocados significados situacionais que, afinal, só provocam ressonância porque também o objeto significa os sujeitos. Essa é a grande dialética apresentada no texto a partir das aventuras de alguns narradores: como fazemos uso dos objetos, ao mesmo tempo que eles fazem uso de nós.

Tecendo fios que se encontram e se desencontram, é possível dizer que José Valmir e, sobretudo, "seu" Muriçoca utilizaram-se dos benefícios que a indumentária pode trazer. Seus trajes eram visíveis e adequados, por isso mesmo seus usuários podiam ser vistos e aceitos.

Em vários momentos de sua vida, "seu" Muriçoca lembra como utilizou argutamente determinada roupa. Evidentemente, não inclui no seu texto a última de suas indumentárias planejadas. Afinal, cabe a mim contar a história do "figurino" que escolheu para narrar suas aventuras durante os quatro anos de entrevistas.

É o filho mais velho de uma família de cinco irmãos. Seus pais se conheceram ainda crianças. Namoraram e, a duras penas, casaram-se no ano de 1913. "Seu" Muriçoca veio ao mundo um ano depois, exatamente no dia 3 de setembro de 1914, no município do Crato (CE). "Havia soldados por todos os lados", ressalta:

Quando foi em 14, no dia 3 de setembro de 1914, eu vim ao mundo. Eu nasci no dia 3 de setembro de 1914. Na época da Primeira Guerra Mundial. Naquela época existia outra guerra em Juazeiro, a revolução do Juazeiro do padre Cícero, do doutor Floro. Houve aquelas questões lá no Juazeiro. Ainda hoje, muitas vezes encontra parte das trincheiras.

guerra?

Kênia - O senhor lembra o que o povo comentava dessa

- Não. Eu nasci nesse ano. Venho trazendo essa história porque meu pai me contou e eu venho colhendo outros conhecimentos.

Essa foi a primeira referência de "seu" Muriçoca sobre os acontecimentos que rodeavam o ano em que nasceu. A guerra, ou melhor, muitas guerras marcam o ano de seu nascimento, não só a da "Tríplice Aliança contra a Tríplice 
Entente", ou a do "Juazeiro", mas também a guerra de seu pai para conseguir se casar, e muitas outras ao longo de sua vida. "Seu" Muriçoca entendeu precocemente que os fardados faziam parte da composição do mundo pequeno (a cidade do Crato) e do mundo grande. As notícias da Primeira Guerra chegavam pelos jornais e circulavam "no boca a boca". Na primeira oportunidade que teve, entregou-se aos trajes oficiais. Daquele dia em diante, jamais deixou de vestir-se convenientemente, na certeza de que a indumentária comunicava valores e situações jamais conseguidos com a palavra. Naqueles dias, a voz de Cassiano tornava-se audível a partir do corpo na farda, objeto gerador que lança o usuário numa infinidade de novas e velhas conexões com o mundo. Como sugere Régis Ramos,

o objeto gerador é gerado na potência de ser atravessado pelo olhar, de ser emotivo e dramático, ou sutil e quase imperceptível, mas sempre indutor ( ou receptor) de novas configurações da percepção (Ramos, 2004: 151).

Depois de assistir a cinema gratuito e enganar o tenente da cidade, era hora de procurar emprego. Na terça-feira, Cassiano, Zé Ferreira e Chiquim novamente se fardaram e foram procurar serviço. Havia um campo de concentração justamente na cidade do Crato. "Os campos eram grandes espaços cercados e vigiados, que concentraram os flagelados durante a seca de 1932” (Rios, 2001: 14).

Mesmo com a suspensão das passagens de trem, os retirantes continuavam a chegar em Fortaleza, vindos do interior. Eram, portanto, nesses centros de aglomeração que o controle do flagelado deveria apresentar maior rigor.

Com a ideia dos campos, o governo procurava diluir as tensões que se constituíam nos "pontos de trem" e, ao mesmo tempo, tentava evitar a migração para a capital pelas vias férreas. A localização dos campos possibilitava um maior controle sobre a vida do retirante. Além da cidade de "seu" Muriçoca (Crato), existiam mais seis campos às margens de outras estações ferroviárias: o campo do Patu, no município de Senador Pompeu; o campo do município de Ipu; o campo do município de Cariús; o campo do município de Quixeramobim e os dois campos de Fortaleza (Tauape ou Matadouro, e Urubu ou Pirambu) (Rios, 2001: 32).

Não fosse pelo "poder mágico" da indumentária, Muriçoca seria mais um a rogar por espaço no trem, ou, por outra, seria um dos concentrados. Na melhor das hipóteses, teria logrado a função de "guarda-concentrado", com traje feito de saco de farinha. Mas a "roupa especial" de Muriçoca colocou-lhe na elite dos campos. 
"Seu" Muriçoca desconfiou que tal lugar necessitava de homens fardados, e estava certo. Todos os campos eram vigiados durante o dia e a noite. $\mathrm{Na}$ concentração do Patu, por exemplo, "o serviço de polícia era feito por duas turmas com 36 homens, divididos em cinco postos durante o dia e seis no correr da noite" (O Povo, 25/05/1932).

Nos campos da capital, a vigilância era efetivada por soldados do $23^{\circ} \mathrm{Ba}-$ talhão de Caçadores, o $23^{\circ} \mathrm{BC}$. Já nos campos espalhados pelo sertão, onde a presença de soldados era mais difícil, alguns guardas eram os próprios flagelados. Aqueles que aderiam mais rapidamente ao projeto de controle eram colocados em postos de vigilância. Desse modo, os escolhidos eram expostos como homens premiados por suas condutas, embora continuassem com roupas feitas de saco de farinha.

Contudo, Muriçoca e seus amigos estavam ali para impor respeito no campo de concentração do Buriti, que, a exemplo dos campos de Fortaleza, poderia contar com o serviço de soldados devidamente fardados. Percebeu que o emprego estava garantido:

O Zé Soares disse: - Seu capitão, esses rapazes chegaram e tão querendo ficar no serviço.

Ele disse imediatamente: - Nós precisamos desses homes. Você mostra o armamento a esses rapazes que eles estão aptos para o trabalho.

Os exames para testar as habilidades dos novos guardas foram dispensados. A farda se encarregava de tudo. "Seu" Muriçoca observava que os outros guardas não tinham os mesmos privilégios, pois suas fardas eram feitas de um material rústico e precário. Destaca "seu" Muriçoca:

Que moral poderia ter este tipo de fardamento? Porque no Campo já tinha um horror de guarda, mas a roupa era de saco de farinha. Pintavam de vermelho ou azul e isso era a farda dos guarda. Nós vimo aquele horror de mocinha no chão, umas do lado das outras. Nós era só pegando o fuzil e mostrando que sabia. Sem saber fazer coisa nenhuma. A turma toda olhando parecia que era Deus do Céu que tava ali. Nós mesmo ficava admirado como o povo era besta.

O poder em face da sua roupa era largamente partilhado pelo grupo que admirava ou odiava a presença daquele que usava farda oficial. Em entrevista 
que realizei no ano de 1996, "seu" Mauro, concentrado no campo de Senador Pompeu, conta que os fardados abusavam do poder, confiavam-se na roupa e levavam a melhor:

A carne boa era só pra eles lá, os grandão. Os guarda maltratava o povo. Os guarda porque anda com aquela farda, aquele cacete, aquela arma, pensa que é uma grande autoridade e devia ser uma coisa qualquer.

A narrativa de "seu" Mauro põe em risco o poder que "seu" Muriçoca reafirmava com o uso do traje especial. Apesar da roupa, "seu" Mauro desconfiava que o guarda podia ser um dos concentrados. Por outro lado, identifica naqueles objetos o motivo para o uso exagerado do poder. Sabe que vem dali a confiança dos "grandões". Atribui aos guardas uma potência que se conecta com a extensão momentânea do corpo pelo uso daquele traje. Despojados, voltariam a ser "uma coisa qualquer". Voltaria a ser, por exemplo, Cassiano, rapaz pobre que deixou a família passando fome, ansiosa pela chegada da comida que o filho soldado traria do campo.

Semelhante aversão acontecia, em São Paulo, com os fardados da Revolução Constitucionalista de 1932. Ao que tudo indica, "seu" Muriçoca e seus amigos não foram os únicos a tirar proveito da farda de defensores da pátria naquele ano. Holien Gonçalves Bezerra, em seu estudo sobre esse conflito, destaca o trecho de um romance de Haddock Lobo sobre a referida guerra. $\mathrm{O}$ trecho aponta para um diálogo entre um grupo de pessoas sobre um combatente do front:

- Por que há tantos rapazes fardados na cidade? - Ah... são os "4F". - Que é isso "4F"? - Você ainda não sabe? Ficam fardado fazendo fita... há também os " $5 \mathrm{~F}$ ": ficam fardado fazendo fita e filando... Filando o quê? - Filando bóia na casa do soldado, e andando de bonde sem pagar. Nós ficamos indignados quando vemos estes rapazes fortes se exibindo assim, longe do perigo... (Bezerra, 1988: 39-40).

No outro extremo do país, com o mesmo tipo de farda, Muriçoca se fazia, em certo sentido, um " $5 \mathrm{~F}$ ". Contudo, na sua memória, era estimado pelos moradores da cidade. Sua presença - ou melhor, a presença dos fardados - enaltecia as ruas do município. Naqueles dias, Cassiano era homem importante, mas sabia que, fora da roupa, a vida dele se assemelhava à dos outros, daqueles que, chegando no campo, eram travestidos em saco de farinha. 
No campo de concentração de Senador Pompeu, dona Perpétua observa que os retirantes estavam divididos em três cores: para alguns vermelho, para outros azul, e para os mortos, "saco de farinha sem cor". Dona Perpétua atribui aos "mortos da concentração" uma força milagrosa devido ao sofrimento que passaram em vida. Entre os padecimentos marcantes, destaca o uso de sacos como roupa e como mortalha:

(...) ali tem corpo santo, muita alma milagrosa. Eu vou dizer pra você. Porque eles se interravam e as mortaia era de saco, daqueles saco de feijão. Foram enterrado em valado, como quem enterra qualquer coisa.

Apesar do repetido uso da palavra "coisa" para designar aquilo que não tem valor, os narradores ressaltam justamente a força da presença ou ausência das "coisas" como fato para tornar alguém "uma coisa qualquer". As pessoas ganham ou perdem privilégios em nome do uso das "coisas", constituindo assim as múltiplas faces da cultura material. "Pensam que são alguma coisa por causa da farda" e despojados da indumentária seriam "uma coisa qualquer".

Neste texto, o objeto é a roupa. Não por acaso, os concentrados eram despojados de suas vestes cotidianas para vestir sacos. Isso lembra as palavras de Stallybrass:

(...) o que fizemos com as coisas para devotar-lhes um tal desprezo? E quem pode se permitir ter esse desprezo? Por que os prisioneiros são despojados de suas roupas a não ser para que se despojem de si mesmos? (Stallybrass, 2000: 108).

Mesmo com a desconfiança e indignação de "seu" Mauro em relação aos guardas do Campo, foi com a "coisa roupa", ou melhor, a farda, que "seu" Muriçoca ("uma coisa qualquer") garantiu o sustento da família, durante a seca de 1932. Ele assumiu um cargo importante, era o chamador, ou seja, o encarregado de controlar a quantidade de ração distribuída às famílias de acordo com o número de membros. Mas a função exigia confiança e alguns conhecimentos, como saber ler e escrever. Conta que se viu em grandes aperreios, pois tinh frequentado pouco a escola e conhecia vagamente a arte da leitura, não obstante exercesse como ninguém o dom da palavra; além do mais, estava devidamente vestido. Com muito jeito, conseguiu desenvolver o ofício.

Depois de garantir emprego em um posto de importância, "seu" Muriçoca recebia, além do salário, sacas de comida, que ele mesmo não precisava levar 
para casa, pois havia encarregados só para isso. Era de se espantar tamanho privilégio. O traje apropriado (a composição entre o corpo e a roupa) constrói possibilidades de inserção legitimada pelo valor da coisa roupa, no sentido em que ela se constitui como elemento da cultura material do grupo. O alcance dessa estima é experimentado de muitas maneiras. Interessa, portanto, estudar o uso que os sujeitos fazem da indumentária, dando movimento às coisas na medida em que são movimentados por elas. Uma história social da indumentária faz ecoar as formas em que panos, fazendas, tecidos e botões se juntam para traduzir a vida. Como infere Beatriz Sarlo, em seu estudo sobre Raymond Willliams:

Nunca se podem estudar objetos como entidades estáticas, já definidas. Os artefatos culturais se fazem de contrastes, (...) ou pelo menos da co-presença de tendências. São compostos de tempos e experiências sociais diferenciadas (apud Ramos, 2004: 36).

Por isso mesmo, as fardas de "seu" Muriçoca não foram escritas como uniformes, sinônimo inadequado para dar conta das múltiplas formas que o traje experimentou ao longo de suas aventuras.

Durante a seca de 1958, o governo federal distribuiu comida e roupas. Aliás, essa medida se repete em relação aos pobres. Dona Cezita - que, em suas narrativas, junta memória e roupas - lembra bem os vestidinhos "que ganhou do presidente Juscelino". Eram "curtinhos, plissados com umas florzinhas roxinhas". A memória de dona Cezita, em alguns momentos, recorda a roupa que vestia naquele dia narrado. Sobre esse movimento da memória, alguns teóricos arriscam dizer que se trata de uma característica da memória feminina. Como sintetiza Michelle Perrot, "a memória das mulheres é trajada" (Perrot, 1989: 13).

Mas o que dizer da memória de "seu" Muriçoca? Suas fardas constituem um centro de lembrança nas histórias de sua vida: uma memória que também é trajada. Por outro lado, não se traduz em uma vestimenta cotidiana; trata-se de uma farda, símbolo de poder. Certamente, aí reside a principal diferença entre os "vestidinhos plissados" de Cezita e a roupa narrada por Muriçoca.

Em meio a essa infinidade de ligações da cultura material, definida entre indivíduos e roupas, é difícil dimensionar a intensidade de todas as conexões que se tecem em face da vestimenta. Não por acaso, Muriçoca, apesar de se compor primorosamente com sua farda, admirava-se com as reações dos conterrâneos diante do objeto. Tais cruzamentos são constituídos historicamente, edificam-se no tempo e no espaço. Não há fixidez de valores relacionados aos objetos. Eles ganham significância na dinâmica dos sentidos. 
Nosso astucioso "soldado" entende esse período como um marco. Julga ser o momento em que começou a perder a inocência e a entender as tramoias do mundo. Ao mesmo tempo, participava intensamente dessas tramas, embora de outro lugar. "Seu" Muriçoca soube manipular e criar possibilidades diante do uso da farda. Não foi à toa que ele se fardou para arranjar o emprego.

Há, aqui, uma inversão momentânea: pela primeira vez, "seu" Muriçoca estava do outro lado, podia conceder favores. Nesse trecho da narrativa, ele evoca o princípio de uma perda da inocência, quando passa para outra margem, quando "começa a entender as coisas como era". A farda propiciou-lhe momentos jamais vividos, e ele usufruiu todas as vantagens que apareceram, inclusive a de narrá-la do jeito que mais lhe agradava, a partir das atualizações próprias da memória oral em face, também, das novas experiências constitutivas da cultura material na cidade, lugar que habitava no momento das entrevistas.

\section{Referências bibliográficas}

BAUDRILLARD, Jean. O sistema dos objetos. São Paulo: Perspectiva, 2000.

BEZERRA, Holien Gonçalves. O jogo do poder. Revolução Paulista de 32. São Paulo: Moderna, 1988.

CERTEAU, Michel de. A invenção do cotidiano: 1. Artes de fazer. Petrópolis: Vozes, 1994.

LATOUR, Bruno. Famais fomos modernos: ensaio de antropofagia simétrica. São Paulo: Editora 34, 1994.

MELLO E SOUZA. Gilda de. O espírito das roupas. A moda no século XIX. São Paulo: Companhia das Letras, 1996.

MENEZES, Ulpiano Bezerra de. Memória e cultura material: documentos pessoais no espaço público. Estudos Históricos, Rio de Janeiro, vol.11, n 21,1998 , p. 89-103.
PAVIANI, Jayme. Formas do dizer. Questões de método, conhecimento e linguagem. Porto Alegre: EDIPUCRS, 1998.

PERROT, Michelle. Práticas da memória feminina. Revista Brasileira de História, São Paulo, v. 9, n. 18, ago.- set. 1989, p. 9-18.

RAMOS, Francisco Regis Lopes. A danação do objeto. O museu no ensino de História. Chapecó: Argos, 2004.

RIOS, Kênia Sousa. Campos de concentração no Ceará. Fortaleza: Museu do Ceará/Secult, 2001.

ROCHE, Daniel. História das coisas banais. Nascimento do consumo (século XVII-XIX). Rio de Janeiro: Rocco, 2000.

STALLYBRASS, Peter. O casaco de Marx: roupas, memória, dor. $2^{\mathrm{a}}$ ed. Belo Horizonte: Autêntica, 2000. 


\section{Resumo}

$\mathrm{O}$ artigo apresenta as estratégias de sobrevivência de um retirante durante as secas no Ceará. "Seu" Muriçoca reelabora a vida por meio dos usos que faz de certos objetos. Ele constrói percursos e formas de escapar da seca em face de uma leitura muito astuciosa sobre o poder da farda. Os sentidos do uniforme vão sendo construídos numa conexão com a vida cotidiana dos retirantes a partir das narrativas de "seu" Muriçoca.

Palavras-chave: indumentária; seca; narrativa; oralidade; cultura material; memória.

\section{Abstract}

The article presents the survival strategies of a migrant during the droughts in Ceará. Mister Muriçoca reworks his life by appropriating certain objects. Through a very astute empowering of his uniform, he builds routes and ways to escape the drought. Based upon Mr. Muriçoca's narratives, the uniform acquires senses that are constructed in connection with the daily life of other migrants

Key words: clothing; drought; narrative; orality; material culture; memory.

\section{Résumé}

Larticle présente les stratégies de survie d'un migrant de l'État de Ceará pendant les sécheresses. Monsieur Muriçoca retravaille sa vie en faisant l'utilisation de certains objets. Il construit les routes et les moyens d'échapper à la sécheresse à travers une lecture très astucieuse de la puissance de son uniforme. Monsieur Muriçoca renforce les sens de l'uniforme en connexion avec la vie quotidienne des migrants..

Mots-clés: vêtements; sécheresse; recits; oralité; culture matérielle; mémoire. 